\title{
Curcumin-induced downregulation of Axl receptor tyrosine kinase inhibits cell proliferation and circumvents chemoresistance in non-small lung cancer cells
}

\author{
KYUNG-CHAN KIM ${ }^{1}$, SUK-HWAN BAEK ${ }^{2}$ and CHUHEE LEE ${ }^{2}$ \\ ${ }^{1}$ Department of Internal Medicine, College of Medicine, Catholic University of Daegu, Daegu 47472; \\ ${ }^{2}$ Department of Biochemistry and Molecular Biology, School of Medicine, \\ Yeungnam University, Daegu 42415, Republic of Korea
}

Received August 30, 2015; Accepted October 13, 2015

DOI: $10.3892 /$ ijo.2015.3216

\begin{abstract}
Lung cancer is still in the first place in terms of both incidence and mortality. In the present study, we demonstrated the effect of curcumin, a phytochemical of the plant Curcuma longa, on expression and activation of Axl receptor tyrosine kinase (RTK) which plays an important role in cell survival, proliferation and anti-apoptosis. Curcumin treatment of nonsmall cell lung cancer (NSCLC) A549 and H460 cells, was found to decrease Axl protein as well as mRNA levels in a dose- and time-dependent manner. Axl promoter activity was also reduced by curcumin, indicating that curcumin downregulates Axl expression at the transcriptional level. Moreover, Axl phosphorylation in response to binding of its ligand, Gas6, was abrogated by curcumin, suggesting the inhibitory effect of curcumin on Gas6-induced Axl activation. We next found cytotoxic effect of cucumin on both the parental A549 and H460 cells, and their variants which are resistant to cisplatin (A549/CisR and H460/CisR) and paclitaxel (A549/TR and H460/TR). Exposure of these cells to curcumin resulted in dose-dependent decline of cell viability and clonogenic ability. It is further observed that the anti-proliferative effect of curcumin on A549 cells overexpressing Axl protein was reduced, while that on $\mathrm{H} 460$ cells transfected Axl specific siRNA was augmented, confirming that curcumin inhibits cell proliferation via downregulation of Axl expression. In addition, curcumin was found to cause the induction of $\mathrm{p} 21$, a
\end{abstract}

Correspondence to: Dr Chuhee Lee, Department of Biochemistry and Molecular Biology, School of Medicine, Yeungnam University, 170 Hyun-Chung Road, Daegu 42415, Republic of Korea

E-mail: chlee2@ynu.ac.kr

Abbreviations: EGFR, epidermal growth factor receptor; Gas6, growth arrest-specific 6; NSCLC, non-small cell lung cancer; RTK, receptor tyrosine kinase; XIAP, X-linked inhibitor of apoptosis

Key words: Axl, chemoresistance, curcumin, Gas6, non-small cell lung cancer, receptor tyrosine kinase, X-linked inhibitor of apoptosis cyclin-dependent kinase inhibitor, and reduction of X-linked inhibitor of apoptosis protein (XIAP), an anti-apoptotic molecule, in parental H460 cells as well as chemoresistant cells, H460/CisR and H460/TR. Taken together, our data imply that Axl RTK is a novel target of curcumin through which it exerts anti-proliferative effect in both parental and chemoresistant NSCLC cells.

\section{Introduction}

Worldwide, lung cancer is the most frequently diagnosed cancer and the leading cause of cancer deaths (1). Approximately $85-90 \%$ of lung cancer is non-small cell lung cancer (NSCLC) which is characterized by relatively low growth rate and poor responsiveness upon chemotherapy, compared to small cell lung cancer (SCLC) (2). Although platinum or taxol-based chemotherapy has been the standard treatment for NSCLC patients, the intrinsic and acquired resistances to these drugs are the major obstacles to achieve the successful long-term outcomes. To overcome the resistance, the second line or combination chemotherapy regimens have been used (3-5), but the overall survival benefits of various chemotherapies in NSCLC is not yet satisfactory.

The large receptor tyrosine kinase (RTK) family in the human genome contains 58 RTKs and is divided into 20 subfamilies. One of the subfamilies is TAM family composed of three RTK members which are Tyro3 (also referred to Brt, Dtk, Rse, Sky or Tif ), Axl (also referred to Ark, Tyro7 or Ufo) and Mer (also referred to Eyk, Nyk or Tyro12) (6-9). Each of them has similar structural features, which are extracellular domains, two immunoglobin-like and two fibronectin type III domains and cytoplasmic kinase domain $(10,11)$. Among several ligands including growth arrest-specific 6 (Gas6), protein S, tubby and tulip, Gas6 is the only one able to bind and activate all three TAM RTKs, which evokes transduction of many extracellular signals to cause cell growth, survival, proliferation, migration and inhibition of apoptosis $(11,12)$.

Since the first identification of Axl in 1988, Axl cDNA was cloned in 1991 from chronic myelogenous leukemia patients as a novel RTK (7). Axl overexpression and its activation 
upon Gas6 stimulation have been reported in many types of cancer such as acute leukemia (13), breast (14), colon (15), esophageal, lung (16), ovarian (17), prostate (18) and thyroid cancer (19), which subsequently signals for cell survival and proliferation (20-22). For example, in more than half of nonsmall cell lung cancer (NSCLC) cell lines, the levels of Axl, Mer and ligands, Gas6 and protein S, were elevated (23-25). In $48.3 \%$ of clinical samples of lung adenocarcinoma, Axl overexpression was observed, which was also associated with disease stages and lymph node metastasis (25). Therefore, Axl has been receiving increased attention as a potent therapeutic target for cancer treatment.

Curcumin, a polyphenolic compound extracted from Curcuma longa, is a well-known natural product with antioxidant, anti-inflammatory and anticancer activities $(26,27)$. Recent clinical investigations demonstrated that curcumin has not only chemo-preventive, but also therapeutic potential in many types of cancer. Moreover, oral administration of up to $12 \mathrm{~g} /$ day of curcumin was reported to be safe enough, suggesting its low toxicity at effective dose. Curcumin has also been demonstrated to modulate many signal transduction pathways involved in survival, carcinogenesis and apoptosis (28-30).

In the present study, we examined the effect of curcumin on expression and activation of Axl RTK in NSCLC cells, which subsequently inhibits cell proliferation and overcomes chemoresistance via both induction of $\mathrm{p} 21$ and reduction of X-linked inhibitor of apoptosis (XIAP), suggesting that Axl RTK is a novel target of curcumin to exert its anticancer activity.

\section{Materials and methods}

Reagents and antibodies. Curcumin was obtained from Sigma-Aldrich (St. Louis, MO, USA). A549 and H460 cells were purchased from the American Type Culture Collection (ATCC; Manassas, VA, USA). Primers for Axl were synthesized by the domestic company, Bioneer Corp. (Daejeon, Korea). TRI reagent was obtained from Solgent Co., Ltd. (Daejeon, Korea). AmpliTaq DNA polymerase and Lipofectamine 2000 were obtained from Roche Diagnostics Corp. (Indianapolis, IN, USA) and Invitrogen (Carlsbad, CA, USA), respectively. G418 was from Gibco-BRL (Gaithersburg, MD, USA). The plasmid, pGL3-basic vector and the Dual-Glo luciferase assay kit were purchased from Promega Corp. (Madison, WI, USA). For western blot analysis, specific antibodies against Axl, cyclin D1, p21, XIAP and GAPDH, as well as secondary antibodies were obtained from Santa Cruz Biotechnology (Dallas, TX, USA).

Cell culture and establishment of cisplatin and paclitaxelresistant cells. The A549 and $\mathrm{H} 460$ cells were grown in RPMI-1640 medium (Gibco-BRL) containing 10\% fetal bovine serum (FBS), $2 \mathrm{mM}$ L-glutamine, $10 \mathrm{U} / \mathrm{ml}$ penicillin and $10 \mathrm{~g} / \mathrm{ml}$ streptomycin at $37^{\circ} \mathrm{C}$ in $5 \% \mathrm{CO}_{2}$ in a watersaturated atmosphere. The variants of A549 and H460 cells which are resistant to cisplatin (A549/CisR and H460/CisR) or paclitaxel (A549/TR and H460/TR cells) were established by stepwise exposure of the parental cells to escalating concentrations of cisplatin (ranging from 0.5 to $2 \mathrm{mM}$ ) and paclitaxel (ranging from 3 to $24 \mathrm{nM}$ ), respectively.
Reverse transcription PCR (RT-PCR). Cells $\left(2 \times 10^{5}\right)$ were seeded in a $60-\mathrm{mm}$ culture dish and grown overnight. They were then treated with the indicated concentrations $(0,5,10$ and $20 \mu \mathrm{M}$ ) of curcumin for $24 \mathrm{~h}$. Total RNA was extracted using TRI reagent and subjected to cDNA synthesis and PCR. The specific primers were as follows: Axl sense, 5'-AACCTT CAACTCCTGCCTTCTCG-3' and antisense, 5'-CAGCTTCT CCTTCAGCTCTTCAC-3'; GAPDH sense, 5'-GGAGCCAA AAGGGTCATCAT-3' and antisense, 5'-GTGATGGCATG GACTGTGGT-3'. The mRNA level of Axl was normalized to that of GAPDH.

Promoter activity test. The promoter reporter plasmid, pGL3Axl, which contains the $A x l$ promoter region ranging from -887 to +7 bp of the transcriptional start site was amplified by PCR and subcloned into the pGL3-basic vector, the luciferase reporter plasmid. The constructed promoter reporter plasmid was co-transfected into cells $\left(3 \times 10^{5}\right.$ cells in a $60-\mathrm{mm}$ dish) with Renilla luciferase vectors, pRL-SV40, as an internal control. Luciferase activity was measured using a Dual-Glo luciferase assay system.

Western blot analysis. Total cell lysates were prepared from the parental or chemoresistant cells treated with the indicated concentrations $(0,5,10$ and $20 \mu \mathrm{M})$ of curcumin using lysis buffer [1\% Triton X-100, $50 \mathrm{mM}$ Tris (pH 8.0), $150 \mathrm{mM} \mathrm{NaCl}$, $1 \mathrm{mM}$ PMSF, $1 \mathrm{mM} \mathrm{Na} \mathrm{VO}_{4}$ and protease inhibitor cocktail]. Untreated cells were used as controls. Protein concentrations were determined using Bio-Rad protein assays. Proteins from the cell lysates (20-40 $\mu \mathrm{g})$ were separated by $12 \%$ SDS-PAGE, and electrotransferred onto nitrocellulose membranes. The membranes were blocked for $30 \mathrm{~min}$ at room temperature in Tris-buffered saline with $0.05 \%$ Tween-20 (TTBS) containing $5 \%$ non-fat dry milk, and then incubated with TTBS containing a primary antibody for $4 \mathrm{~h}$ at room temperature. After 3x10 min washes in TTBS, the membranes were incubated with peroxidase-conjugated secondary antibody for $1 \mathrm{~h}$. Following 3 additional 10 -min washes with TTBS, the protein bands of interest were visualized using an enhanced chemiluminescence detection system (Amersham ${ }^{\mathrm{TM}} \mathrm{ECL}^{\mathrm{TM}}$ Prime Western Blotting Detection reagent; GE Healthcare, Piscataway, NJ, USA).

Cell viability measurement. To assess cell viability, the number of viable cells was counted using Trypan blue. Briefly, $3 \times 10^{3}$ cells were seeded into $60-\mathrm{mm}$ culture dish, grown overnight and then treated with the indicated concentrations $(0,5,10$ and $20 \mu \mathrm{M})$ of curcumin for $24 \mathrm{~h}$. After curcumin treatment, cells were harvested and stained with $0.4 \%$ Trypan blue solution. Dye-excluding viable cells were counted under the microscope. Cell viability was also expressed as a percentage of the viable cells with respect to untreated control cells.

Clonogenic assay. Cells were seeded into $24-w e l l$ plates $\left(1 \times 10^{2}\right.$ cells/well) and treated with the indicated concentrations $(0,5$, 10 and $20 \mu \mathrm{M}$ ) of curcumin for $24 \mathrm{~h}$. Curcumin-treated cells were then cultured for the next 7-10 days to form colonies. Colonies of $>50$ cells were stained with Crystal violet (in $60 \%$ methanol; Junsei Chemical Co., Ltd., Tokyo, Japan) and 
images were acquired using the RAS-3000 Image Analysis System (FujiFilm, Tokyo, Japan).

Ectopic expression of Axl. To ectopically express Axl, the recombinant plasmid, pcDNA3-Axl, was constructed by cloning the Axl cDNA into the EcoRI and BamHI sites of the pcDNA3 vector and $2 \mu \mathrm{g}$ of purified plasmids were transfected into the A549 cells ( $3 \times 10^{5}$ cells in a $60 \mathrm{~mm}$ dish) using Lipofectamine 2000 (Invitrogen). To establish stable cell lines, which constitutively express Axl, the transfected cells were cultured in the presence of $400 \mu \mathrm{g} / \mathrm{ml}$ of G418. The RPMI1640 medium containing G418 was refreshed every 3 days. After 3-4 weeks, the Axl-expressing cells were enriched and the Axl expression in these cells was analyzed by western blot analysis.

Transfection of siRNA. To reduce Axl expression, RNA interference-mediated gene silencing was performed. Cells $\left(3 \times 10^{5}\right)$ were seeded in $60-\mathrm{mm}$ culture dishes, grown overnight and then transfected with $50 \mathrm{nM}$ siRNA targeting Axl (sense, 5'-AAGAUUUGGAGAdACACACUGA-3' and antisense, 5'-UCAGUGUGUUCUCCAAAUCUU-3'), as previously described (30) or control siRNA. The cells were harvested for 24 and $48 \mathrm{~h}$ after transfection and used to evaluate protein expression and cell proliferation, respectively.

Statistical analysis. Data were expressed as the means \pm SD of triplicate samples or at least three independent experiments. To determine statistical significance, the Student's t-test was used with a P-value threshold of $<0.05$.

\section{Results}

Curcumin suppresses expression of Axl receptor tyrosine kinase at transcriptional level. We first examined if curcumin alters expression of Axl receptor tyrosine kinase (RTK) in the lung cancer A549 and H460 cells. After treatment of cells with 5,10 and $20 \mu \mathrm{M}$ curcumin for $24 \mathrm{~h}, \mathrm{Axl}$ protein level was determined by western blot analysis. The results of western blot analysis showed that Axl protein level in curcumin-treated cells was reduced in the dose-dependent manner (Fig. 1A). Additionally, this inhibitory effect of curcumin on Axl expression was also time-dependent, since Axl protein level was found to gradually decrease, when these cells were treated with $20 \mu \mathrm{M}$ curcumin for 6,12 and $24 \mathrm{~h}$ (Fig. 1B).

Downregulation of Axl expression by curcumin was further demonstrated by RT-PCR. Consistent with western blot results, Axl mRNA levels of A549 and H460 cells were also markedly and dose-dependently diminished by the indicated concentrations of curcumin (Fig. 1C). Moreover, the effect of curcumin on transcription of the $A x l$ gene was examined using the $A x l$ promoter-luciferase reporter plasmid, pGL3-Axl. As shown in Fig. 1D, luciferase activities of A549 cells transfected with pGL3-Axl and treated with 5, 10 and $20 \mu \mathrm{M}$ curcumin for $6 \mathrm{~h}$ were significantly declined, indicating that curcumin inhibits Axl expression at the transcriptional level.

Curcumin inhibits activation of Axl upon the growth arrestspecific gene 6 stimulation. Binding of growth arrest-specific gene 6 (Gas6), a validated ligand, to Axl results in its activation,
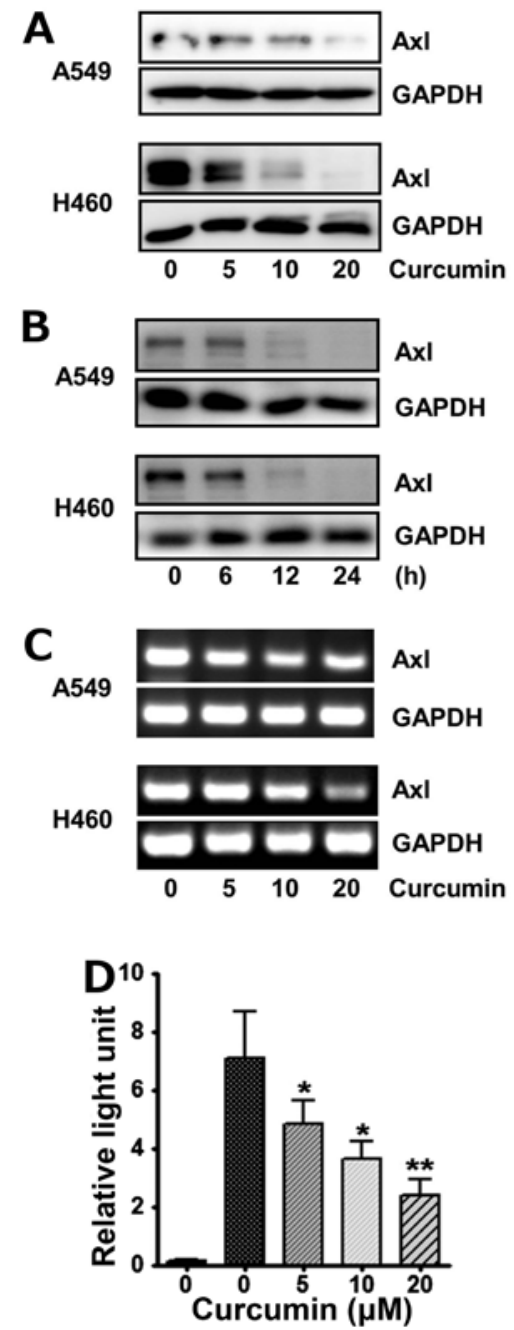

Figure 1. Curcumin decreases Axl expression at transcriptional level. Cells $\left(3 \times 10^{3}\right.$ cells/dish) were seeded onto $60-\mathrm{mm}$ dishes, grown overnight and exposed to curcumin. (A) A549 or H460 cells were treated with 5, 10 and $20 \mu \mathrm{M}$ curcumin for $24 \mathrm{~h}$ and then cells were harvested. (B) A549 or H460 cells were treated with $20 \mu \mathrm{M}$ curcumin for 6,12 and $24 \mathrm{~h}$ and then cells were harvested. Axl protein levels were determined by western blot analysis. GAPDH was used as a loading control. The result shown is a representative of three independent experiments. (C) For RT-PCR, total RNAs from the cells treated with the indicated concentrations of curcumin for $12 \mathrm{~h}$ were isolated and used to determine $A x l$ mRNA levels. As an internal control, GAPDH mRNA was also amplified by RT-PCR. The data shown are a representative of three independent experiments. (D) To examine the effect of curcumin on A $x l$ promoter activity, the $\mathrm{H} 460$ cells $\left(3 \times 10^{4}\right.$ cells $)$ were transfected with pGL3 or pGL3 Axl using Lipofectamine 2000. The cells were then incubated with $20 \mu \mathrm{M}$ curcumin for $24 \mathrm{~h}$ and total cell lysates were used to measure luciferase activity. Data are expressed as the means \pm SD of triplicate samples conducted in three independent experiments. The asterisks indicate a significant difference compared to the control value ( ${ }^{*} \mathrm{P}<0.05$ and ${ }^{* * *} \mathrm{P}<0.01$, vs. untreated group).

that is the phosphorylation of tyrosine residues at intracellular kinase domain $(31,32)$. We next examined the effect of curcumin on Axl phosphorylation after Gas6 treatment.

Serum-starved A549 and H460 cells were treated with Gas6 for 15, 30, 60 and 120 min and phosphorylated Axl levels were determined by western blot analysis. As illustrated in Fig. 2A, Axl phosphorylation by Gas6 occurred within $15 \mathrm{~min}$ in both cells and returned back to each of their basal levels by $120 \mathrm{~min}$. However, we found that pre-incubation of $\mathrm{H} 460$ cells with curcumin inhibited Gas6-induced Axl phosphorylation 

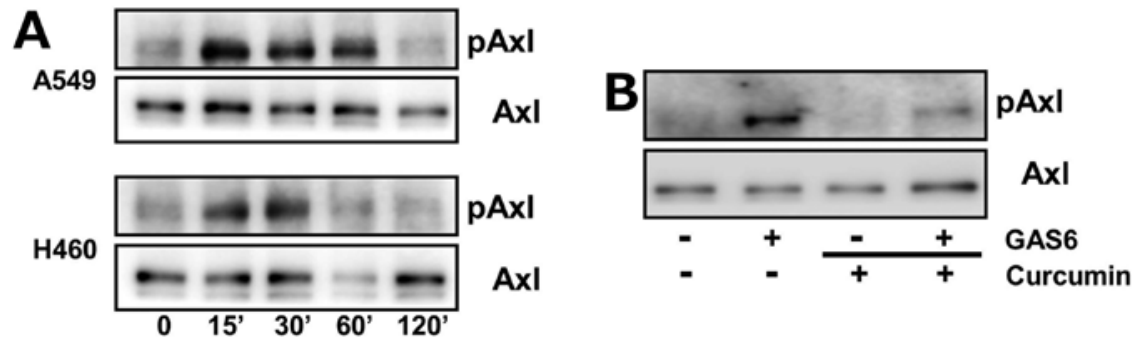

Figure 2. Curcumin inhibits Axl activation upon Gas6 stimulation. Cells ( $3 \times 10^{3}$ cells/dish) were seeded onto 60-mm dishes, serum-starved overnight, and treated with $250 \mathrm{ng} / \mathrm{ml} \mathrm{Gas6}$. (A) A549 or H460 cells were treated with Gas6 for 15, 30, 60 and $120 \mathrm{~min}$ and then harvested. (B) H460 cells were pre-incubated with $20 \mu \mathrm{M}$ curcumin for $60 \mathrm{~min}$, followed with Gas6 treatment and then harvested. Phosphorylated Axl protein levels were determined by western blot analysis. Total Axl protein level was used as a loading control. The result shown is a representative of three independent experiments.
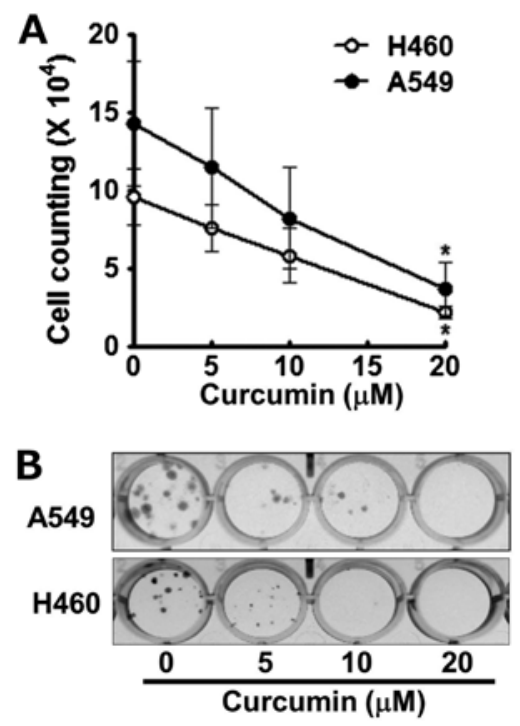

E
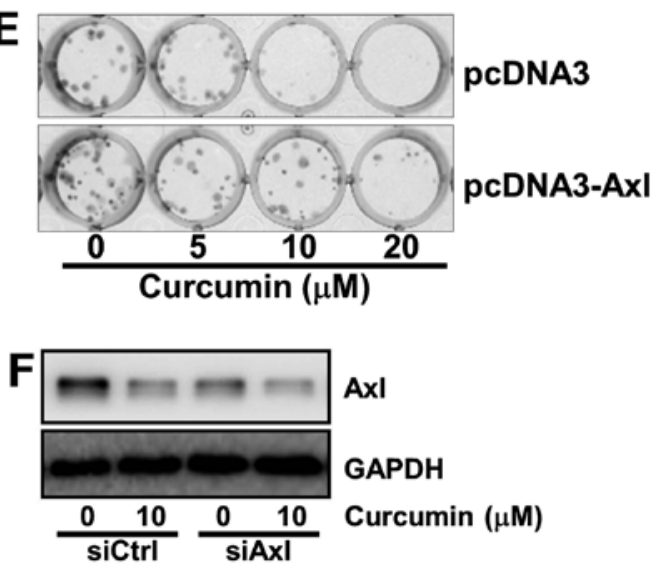
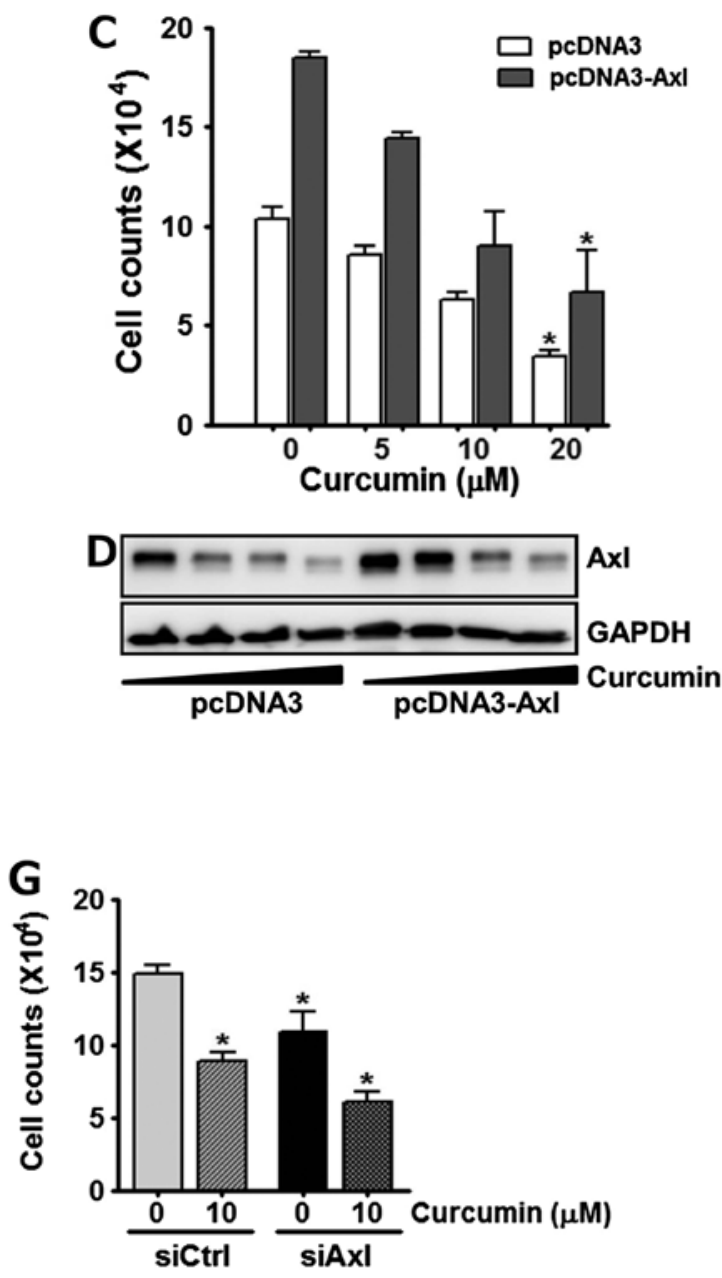

Figure 3. Curcumin inhibits cell proliferation and its anti-proliferative effect is reduced or augmented by Axl protein level. A549 or H460 cells $\left(3 \times 10^{3}\right.$ cells/ dish) were seeded onto 60-mm dishes, grown overnight. (A) Cells were treated with 5, 10 and $20 \mu \mathrm{M}$ curcumin for $24 \mathrm{~h}$ and then harvested. The number of viable cells were counted using trypan blue exclusion assay. Data are represented as mean \pm SD of at least three independent experiments. The asterisks indicate a significant difference compared to the control value (" $\mathrm{P}<0.05$ vs. untreated group). (B) Cells ( $2 \times 10^{3}$ cells/dish) were seeded onto $35-\mathrm{mm}$ dishes, treated with the indicated dose of curcumin for $24 \mathrm{~h}$ and allowed to grow for next 7-10 days. Colonies were visualized by crystal violet staining. The data shown are representative of three independent experiments. (C) A549 cells were transfected with pcDNA3 or pcDNA3-Axl plasmid using Lipofectamine 2000. The transfected cells were treated with the indicated doses of curcumin for $24 \mathrm{~h}$, then harvested, and stained with tryphan blue to count the viable cells. Data are expressed as the means \pm SD from three independent experiments. The asterisks indicate the significant difference compared to the control value ("P<0.05 vs. untreated group). (D) A549/pc-DNA3 and A549/pc-DNA3-Axl cells were treated with the indicated concentrations of curcumin for $24 \mathrm{~h}$. The total cell lysates were prepared and Axl protein level was determined by western blot analysis. (E) Colonogenic assay was also conducted with A549/pc-DNA3 and A549/pc-DNA3-Axl cells exposed to the indicated concentrations of curcumin for $24 \mathrm{~h}$. Colonies formed during 7-10 days of culture were visualized by crystal violet staining. (F) H460 cells ( $3 \times 10^{4}$ cells) were transfected with Axl specific siRNA or control siRNA, respectively. Cells were harvested 24 h posttransfection, divided into two groups, and grown for $24 \mathrm{~h}$ in the presence or absence of $10 \mu \mathrm{M}$ curcumin. The total cell lysates were prepared and Axl protein levels were determined by western blot analysis. GAPDH was used as a loading control and results shown are representative of at least three independent experiments. (G) After curcumin treatment, cells were harvested and stained with tryphan blue to count viable cells. Data are represented as mean \pm SD of at least three independent experiments. The asterisks indicate a significant difference compared to the control value ("P $<0.05$ vs. untreated group). 



(Fig. 2B), suggesting the inhibitory effect of curcumin on Axl activation upon Gas6 stimulation.

Curcumin targets Axl to inhibit cell proliferation. Since overexpression and activation of Axl had been reported to be involved in oncogenesis, cell survival, proliferation and anti-apoptosis $(13,14,20,22)$, we next assessed if the downregulation of Axl by curcumin affects cell viability. The cells were incubated with $0,5,10$ and $20 \mu \mathrm{M}$ of curcumin for $24 \mathrm{~h}$, and the number of viable cells was then counted. As shown in Fig. 3A, treatment of cells with curcumin reduced cell viability in a dose-dependent manner. Of note, following the incubation of A549 and H460 cells with $20 \mu \mathrm{M}$ curcumin, only $30 \%$ and $22 \%$ of the cells survived, respectively.
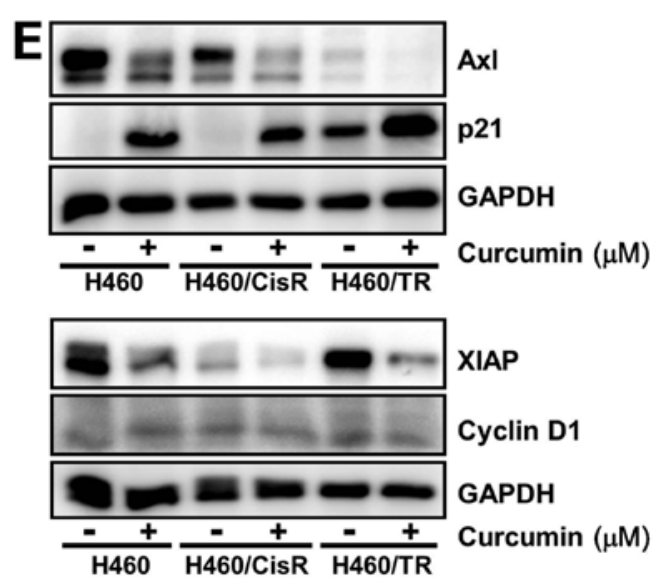

Figure 4. Curcumin inhibits proliferation of cisplatin- and paclitaxel-resistant lung cancer cells and causes induction of p21 as well as reduction of XIAP. Each variants of A549 and H460 cells, which are cisplatin- (A549/ CisR and H460/CisR) and paclitaxel-resistant (A549/TR and H460/TR), respectively, were seeded onto $60-\mathrm{mm}$ dishes, and grown overnight. (A) Cells ( $3 \times 10^{3}$ cells/dish) were treated with 5,10 and $20 \mu \mathrm{M}$ curcumin for $24 \mathrm{~h}$ and then harvested. Axl protein levels were examined by western blot analysis. GAPDH was used as a loading control. The result shown is a representative of three independent experiments. (B and C) Cells ( $1 \times 10^{3}$ cells/dish) were seeded onto 96 -well plates and treated with the indicated concentrations of curcumin for $24 \mathrm{~h}$. Cell proliferation was determined by CCK- 8 assay. The data shown are representative of at least three independent experiments. Data are represented as mean $\pm \mathrm{SD}$. The asterisks indicate a significant difference compared to the control value ( $\mathrm{P}<0.05$ vs. untreated group). (D) Cells ( $2 \times 10^{3}$ cells/dish) were seeded onto 35-mm dishes and treated with 5, 10 and $20 \mu \mathrm{M}$ curcumin for $24 \mathrm{~h}$, and allowed to grow for 7-10 days. The colonies were visualized by crystal violet staining. The data shown are representative of at least three independent experiments. (E) H460, H460/CisR and H460/TR cells $\left(3 \times 10^{3}\right.$ cells/dish) were treated with $10 \mu \mathrm{M}$ curcumin for $24 \mathrm{~h}$ and then harvested. The levels of $\mathrm{p} 21$, cyclin D1 and XIAP protein were determined by western blot analysis. GAPDH was used as a loading control. The result shown is a representative of three independent experiments.

The anti-proliferative effects of curcumin on the A549 and H460 cells were also observed by clonogenic assay. The cells were exposed to the indicated concentrations of curcumin for $24 \mathrm{~h}$ and then allowed to grow for the next 10 days. Curcumin treatment was found to result in the dose-dependent decline of colony formation (Fig. 3B). Specifically, H460 cells as well as A549 cells failed to form visible colonies at 10 and $20 \mu \mathrm{M}$ curcumin, respectively, indicating that curcumin seems to be more cytotoxic toward H460 cells than A549 cells.

To further confirm the involvement of Axl in the antiproliferative effects of curcumin, we examined the cytotoxic effect of curcumin on cells manipulated to enhance or reduce Axl expression. As shown in Fig. 3C, A549 cells transfected with 
pcDNA3-Axl, a recombinant plasmid containing Axl cDNA for its overexpression, were less sensitive to curcumin treatment compared to the control cells transfected with pcDNA3 vector, indicating that $A x l$ overexpression reduced the anti-proliferative effects of curcumin. Western blot analysis consistently showed that the Axl level of the pcDNA3-Axl transfected A549 cells was higher than that of their control cells even after curcumin treatment (Fig. 3D). Colony formation assay also manifested that in contrast to the control cells, Axl-overexpressing A549 cells formed more colonies and were relatively less affected by curcumin treatment (Fig. 3E). Subsequently, H460 cells were transfected with Axl specific siRNA, siAxl, or control siRNA, siCtrl and then treated with curcumin for $24 \mathrm{~h}$. We found that Axl targeting by siAxl significantly decreased Axl expression (Fig. 3F), which resulted in the augmentation of anti-proliferative effect of curcumin (Fig. 3G). Taken together, these results demonstrated that Axl protein level tightly correlates with cell proliferation and verified that curcumin inhibits cell proliferation via downregulation of Axl expression.

Curcumin suppresses proliferation of both cisplatin- and paclitaxel-resistant lung cancer cells and results in the elevation of 221 as well as reduction of XIAP expression. Next, we asked if curcumin could be cytotoxic in the cisplatin- and paclitaxel-resistant NSCLC cells which are the variants of A549 and H460 cells. Each of the variants was established by stepwise exposure of parental cells to increasing concentrations of cisplatin (A549/CisR and H460/CisR cells) or paclitaxel (A549/TR and H460/TR cells), respectively. As shown in Fig. 4A, curcumin reduced the Axl protein levels of A549/TR, A549/CisR, H460/TR and H460/CisR cells in a dose-dependent manner. Notably, in H460/TR cells, the Axl protein level was found to be fairly low and still decreased by curcumin treatment.

In accordance with the western blot results, the viability of both paclitaxel- and cisplatin-resistant cells were dosedependently declined by curcumin treatment. Especially, exposure of cells with $20 \mu \mathrm{M}$ curcumin for $24 \mathrm{~h}$ was found to result in only $41.3 \%$ (A549/TR), 62.8\% (A549/CisR), $15.6 \%$ (H460/TR), 27\% (H460/CisR) survival of these cells, respectively (Fig. 4B and C). Colonogenic activity of curcumin-treated the variants of A549 and H460 cells further showed cytotoxicity of curcumin on these chemoresistant cells. As shown in Fig. 4D, treatment of these cells with curcumin reduced the number of colonies as well as the size of each colony. In contrast to chemoresistant A549 cells, H460/TR and H460/CisR cells were more profoundly affected by curcumin treatment, which are consistent with the result from cell viability measurement.

To demonstrate the intracellular effectors which are involved in the curcumin-mediated downregulation of Axl expression and result in the inhibition of cell proliferation, we assessed the levels of cell cycle regulator, p21 and apoptosis related protein, the $\mathrm{X}$-linked inhibitor of apoptosis protein (XIAP). The H460, H460/TR and H460/CisR cells were treated with $10 \mu \mathrm{M}$ curcumin for $24 \mathrm{~h}$ and western blot analysis showed that curcumin induced the expression of the cyclin dependent kinase inhibitor p21, which causes cell cycle arrest, but reduced that of XIAP, which inhibits apoptosis
(Fig. 4E). Collectively, these results indicate that curcumin downregulates Axl expression, subsequently increases p21 protein level and decreases XIAP protein level, which result in the inhibition of cell proliferation.

\section{Discussion}

Standard chemotherapy for NSCLC has been the combination of platinum-based agents (cisplatin or carboplatin) and a second drug (pemetrexed, gemstabine, paclitaxel or vinorelbine), but low response rate (20-35\%) and eventual development of chemoresistance among initial responders have been the main causes of poor prognosis $(33,34)$. Linger et al (24) have demonstrated that Mer or Axl inhibition enhanced sensitivity of NSCLC cells to various cytotoxic agents such as cisplatin, carboplatin, doxorubicin or etoposide by promoting apoptosis. Since TAM family members of RTKs have been reported to play important roles in cell survival, proliferation and apoptosis (35), targeting of these RTKs seems to be a potent strategy to improve standard chemotherapy regimens.

In the present study, we observed that curcumin had inhibitory effects on Axl expression, Gas6-dependent Axl phosphorylation, and Axl promoter activity in NSCLC cells (Figs. 1 and 2). Silencing of Axl expression by RNA interference or specific monoclonal antibodies against Axl have been demonstrated to inhibit cell proliferation, metastasis and xenograft tumor growth in NSCLC $(36,37)$. Consistent with previous reports, we also observed that curcumin decreased the viability of NSCLC cells (A549 and H460). Moreover, anti-proliferative effect of curcumin was reduced by ectopic expression of Axl and augmented by Axl knockdown using siRNA, respectively, suggesting that curcumin abrogates these A549 and $\mathrm{H} 460$ cell proliferation via downregulation of Axl expression and further confirming that $\mathrm{Axl}$ is a new target of curcumin that contributes to its anticancer effects which have been known to be due to negative regulation of diverse intracellular molecules including transcription factors (38), growth factors, protein kinases (39) and oncogenic proteins (40), resulting in cell cycle arrest and/or apoptosis.

Several reports have shown that curcumin could affect each stage of cancer such as initiation, promotion and progression, ingestion of curcumin was even found to significantly inhibit the activity of lymphocytic glutathione S-transferase, a phase II detoxification enzyme, involved in the development of chemoresistance $(41,42)$. The growing body of evidence also indicates that overexpression and/or activation of $\mathrm{Axl}$ is a novel mechanism to induce the acquired resistance to various anticancer drugs including cytotoxic agents and various tyrosine kinase inhibitors, especially EGF receptor inhibitors (gefitinib or erlotinib) $(43,44)$. Consistently, our data also showed that the viabilities of cisplatin/taxol-resistant cells (A549/CisR, H460/CisR, A549/TR and H460/TR) were decreased by curcumin treatment (Figs. 3A and B and 4B-D) and Axl protein levels of each cell type were also declined by curcumin, implying again that Axl plays a critical role in proliferation of both parental and chemoresistant NSCLC cells and the acquisition of resistance against chemotherapeutic drugs.

In summary, our data indicate that curcumin has inhibitory effects on Axl expression and the activation in response to 
Gas6 binding, which are associated with its anti-proliferative activity in parental as well as each type of cisplatin/paclitaxelresistant NSCLC cells. Thus, Axl seems to be a potent therapeutic target of curcumin to inhibit cell proliferation and to overcome chemoresistance of NSCLC cells.

\section{Acknowledgements}

The present study was supported by the 2014 Yeungnam University Research Grant (no. 214A380116).

\section{References}

1. Siegel R, Ward E, Brawley O and Jemal A: Cancer statistics, 2011: The impact of eliminating socioeconomic and racial disparities on premature cancer deaths. CA Cancer J Clin 61: 212-236, 2011.

2. Devesa SS, Bray F, Vizcaino AP and Parkin DM: International lung cancer trends by histologic type: male:female differences diminishing and adenocarcinoma rates rising. Int J Cancer 117: 294-299, 2005

3. Sandler A, Gray R, Perry MC, Brahmer J, Schiller JH, Dowlati A, Lilenbaum R and Johnson DH: Paclitaxel-carboplatin alone or with bevacizumab for non-small-cell lung cancer. N Engl J Med 355: 2542-2550, 2006

4. Scagliotti GV, Parikh P, von Pawel J, Biesma B, Vansteenkiste J, Manegold C, Serwatowski P, Gatzemeier U, Digumarti R, Zukin M, et al: Phase III study comparing cisplatin plus gemcitabine with cisplatin plus pemetrexed in chemotherapynaive patients with advanced-stage non-small-cell lung cancer. J Clin Oncol 26: 3543-3551, 2008.

5. Schiller JH, Harrington D, Belani CP, Langer C, Sandler A, Krook J, Zhu J and Johnson DH; Eastern Cooperative Oncology Group: Comparison of four chemotherapy regimens for advanced non-small cell lung cancer. N Engl J Med 346: 92-98, 2002.

6. Lai C and Lemke G: An extended family of protein-tyrosine kinase genes differentially expressed in the vertebrate nervous system. Neuron 6: 691-704, 1991

7. O'Bryan JP, Frye RA, Cogswell PC, Neubauer A, Kitch B, Prokop C, Espinosa R III, Le Beau MM, Earp HS and Liu ET: axl, a transforming gene isolated from primary human myeloid leukemia cells, encodes a novel receptor tyrosine kinase. Mol Cell Biol 11: 5016-5031, 1991.

8. Lai C, Gore M and Lemke G: Structure, expression, and activity of Tyro 3, a neural adhesion-related receptor tyrosine kinase. Oncogene 9: 2567-2578, 1994.

9. Graham DK, Dawson TL, Mullaney DL, Snodgrass HR and Earp HS: Cloning and mRNA expression analysis of a novel human protooncogene, c-mer. Cell Growth Differ 5: 647-657, 1994.

10. Heiring C, Dahlbäck B and Muller YA: Ligand recognition and homophilic interactions in Tyro3: Structural insights into the Axl/Tyro3 receptor tyrosine kinase family. J Biol Chem 279: 6952-6958, 2004.

11. Sasaki T, Knyazev PG, Clout NJ, Cheburkin Y, Göhring W, Ullrich A, Timpl R and Hohenester E: Structural basis for Gas6-Axl signalling. EMBO J 25: 80-87, 2006.

12. Lemke $G$ and Rothlin CV: Immunobiology of the TAM receptors Nat Rev Immunol 8: 327-336, 2008.

13. Rochlitz C, Lohri A, Bacchi M, Schmidt M, Nagel S, Fopp M, Fey MF, Herrmann R and Neubauer A: Axl expression is associated with adverse prognosis and with expression of Bcl-2 and CD34 in de novo acute myeloid leukemia (AML): Results from a multicenter trial of the Swiss Group for Clinical Cancer Research (SAKK). Leukemia 13: 1352-1358, 1999.

14. Berclaz G, Altermatt HJ, Rohrbach V, Kieffer I, Dreher E and Andres AC: Estrogen dependent expression of the receptor tyrosine kinase axl in normal and malignant human breast. Ann Oncol 12: 819-824, 2001.

15. Craven RJ, Xu LH, Weiner TM, Fridell YW, Dent GA, Srivastava S, Varnum B, Liu ET and Cance WG: Receptor tyrosine kinases expressed in metastatic colon cancer. Int J Cancer 60: 791-797, 1995.

16. Nemoto T, Ohashi K, Akashi T, Johnson JD and Hirokawa K: Overexpression of protein tyrosine kinases in human esophageal cancer. Pathobiology 65: 195-203, 1997.
17. Rankin EB, Fuh KC, Taylor TE, Krieg AJ, Musser M, Yuan J, Wei K, Kuo CJ, Longacre TA and Giaccia AJ: AXL is an essential factor and therapeutic target for metastatic ovarian cancer. Cancer Res 70: 195-203, 2010.

18. Sainaghi PP, Castello L, Bergamasco L, Galletti M, Bellosta P and Avanzi GC: Gas6 induces proliferation in prostate carcinoma cell lines expressing the Axl receptor. J Cell Physiol 204: 36-44, 2005.

19. Ito T, Ito M, Naito S, Ohtsuru A, Nagayama Y, Kanematsu T, Yamashita S and Sekine I: Expression of the Axl receptor tyrosine kinase in human thyroid carcinoma. Thyroid 9: 563-567, 1999.

20. Hutterer M, Knyazev P, Abate A, Reschke M, Maier H, Stefanova N, Knyazeva T, Barbieri V, Reindl M, Muigg A, et al: Axl and growth arrest-specific gene 6 are frequently overexpressed in human gliomas and predict poor prognosis in patients with glioblastoma multiforme. Clin Cancer Res 14: 130-138, 2008.

21. Sun WS, Fujimoto $\mathrm{J}$ and Tamaya T: Coexpression of growth arrest-specific gene 6 and receptor tyrosine kinases Axl and Sky in human uterine endometrial cancers. Ann Oncol 14: 898-906, 2003.

22. Gustafsson A, Martuszewska D, Johansson M, Ekman C, Hafizi S, Ljungberg B and Dahlbäck B: Differential expression of Axl and Gas6 in renal cell carcinoma reflecting tumor advancement and survival. Clin Cancer Res 15: 4742-4749, 2009.

23. Wimmel A, Glitz D, Kraus A, Roeder J and Schuermann M: Axl receptor tyrosine kinase expression in human lung cancer cell lines correlates with cellular adhesion. Eur J Cancer 37: 2264-2274, 2001.

24. Linger RM, Keating AK, Earp HS and Graham DK: Taking aim at Mer and Axl receptor tyrosine kinases as novel therapeutic targets in solid tumors. Expert Opin Ther Targets 14: 1073-1090, 2010.

25. Shieh YS, Lai CY, Kao YR, Shiah SG, Chu YW, Lee HS and Wu CW: Expression of axl in lung adenocarcinoma and correlation with tumor progression. Neoplasia 7: 1058-1064, 2005.

26. Abe Y, Hashimoto S and Horie T: Curcumin inhibition of inflammatory cytokine production by human peripheral blood monocytes and alveolar macrophages. Pharmacol Res 39: 41-47, 1999.

27. Oyama Y, Masuda T, Nakata M, Chikahisa L, Yamazaki Y, Miura K and Okagawa M: Protective actions of 5'-n-alkylated curcumins on living cells suffering from oxidative stress. Eur J Pharmacol 360: 65-71, 1998.

28. Park W, Amin AR, Chen ZG and Shin DM: New perspectives of curcumin in cancer prevention. Cancer Prev Res (Phila) 6: 387-400, 2013.

29. Sharma RA, Euden SA, Platton SL, Cooke DN, Shafayat A, Hewitt HR, Marczylo TH, Morgan B, Hemingway D, Plummer SM, et al: Phase I clinical trial of oral curcumin: Biomarkers of systemic activity and compliance. Clin Cancer Res 10: 6847-6854, 2004.

30. Dhillon N, Aggarwal BB, Newman RA, Wolff RA, Kunnumakkara AB, Abbruzzese JL, Ng CS, Badmaev V and Kurzrock R: Phase II trial of curcumin in patients with advanced pancreatic cancer. Clin Cancer Res 14: 4491-4499, 2008.

31. Stitt TN, Conn G, Gore M, Lai C, Bruno J, Radziejewski C, Mattsson K, Fisher J, Gies DR, Jones PF, et al: The anticoagulation factor protein $\mathrm{S}$ and its relative, Gas6, are ligands for the Tyro 3/Axl family of receptor tyrosine kinases. Cell 80: 661-670, 1995.

32. Varnum BC, Young C, Elliott G, Garcia A, Bartley TD, Fridell YW, Hunt RW, Trail G, Clogston C, Toso RJ, et al: Axl receptor tyrosine kinase stimulated by the vitamin K-dependent protein encoded by growth-arrest-specific gene 6 . Nature 373: 623-626, 1995.

33. McGuire WP, Hoskins WJ, Brady MF, Kucera PR, Partridge EE, Look KY, Clarke-Pearson DL and Davidson M: Cyclophosphamide and cisplatin compared with paclitaxel and cisplatin in patients with stage III and stage IV ovarian cancer. $\mathrm{N}$ Engl J Med 334: 1-6, 1996.

34. Stordal B, Pavlakis N and Davey R: A systematic review of platinum and taxane resistance from bench to clinic: An inverse relationship. Cancer Treat Rev 33: 688-703, 2007. 
35. Linger RM, Keating AK, Earp HS and Graham DK: TAM receptor tyrosine kinases: Biologic functions, signaling, and potential therapeutic targeting in human cancer. Adv Cancer Res 100: 35-83, 2008.

36. Ye X, Li Y, Stawicki S, Couto S, Eastham-Anderson J, Kallop D, Weimer R, Wu Y and Pei L: An anti-Axl monoclonal antibody attenuates xenograft tumor growth and enhances the effect of multiple anticancer therapies. Oncogene 29: 5254-5264, 2010.

37. Li Y, Ye X, Tan C, Hongo JA, Zha J, Liu J, Kallop D, Ludlam MJ and Pei L: Axl as a potential therapeutic target in cancer: Role of Axl in tumor growth, metastasis and angiogenesis. Oncogene 28: 3442-3455, 2009.

38. Sethi G and Tergaonkar V: Potential pharmacological control of the NF- $\kappa$ B pathway. Trends Pharmacol Sci 30: 313-321, 2009.

39. Dorai T, Gehani N and Katz A: Therapeutic potential of curcumin in human prostate cancer. II. Curcumin inhibits tyrosine kinase activity of epidermal growth factor receptor and depletes the protein. Mol Urol 4: 1-6, 2000.

40. Seol DW, Chen Q and Zarnegar R: Transcriptional activation of the hepatocyte growth factor receptor (c-met) gene by its ligand (hepatocyte growth factor) is mediated through AP-1. Oncogene 19: 1132-1137, 2000.
41. Sharma RA, Ireson CR, Verschoyle RD, Hill KA, Williams ML, Leuratti C, Manson MM, Marnett LJ, Steward WP and Gescher A: Effects of dietary curcumin on glutathione S-transferase and malondialdehyde-DNA adducts in rat liver and colon mucosa: Relationship with drug levels. Clin Cancer Res 7: 1452-1458, 2001.

42. Townsend D and Tew K: Cancer drugs, genetic variation and the glutathione-S-transferase gene family. Am J Pharmacogenomics 3: $157-172,2003$

43. Zhang Z, Lee JC, Lin L, Olivas V, Au V, LaFramboise T, AbdelRahman M, Wang X, Levine AD, Rho JK, et al: Activation of the AXL kinase causes resistance to EGFR-targeted therapy in lung cancer. Nat Genet 44: 852-860, 2012.

44. Rho JK, Choi YJ, Kim SY, Kim TW, Choi EK, Yoon SJ, Park BM, Park E, Bae JH, Choi CM, et al: MET and AXL inhibitor NPS-1034 exerts efficacy against lung cancer cells resistant to EGFR kinase inhibitors because of MET or AXL activation. Cancer Res 74: 253-262, 2014. 